Egyptian

Orthodontic Journal

\title{
ASSOCIATION BETWEEN MALOCCLUSION AND SIGNS OF TEMPOROMANDIBULAR DYSFUNCTION IN FEMALE ADOLESCENTS
}

\author{
Rabab M. Feteih, BDS, Cert. Ortho., DMSc. *
}

ABSTRACT

The aim of the present cross-sectional study was to investigate the association between the different morphologic occlusal characteristics and signs of temporomandibular disorders $(\mathcal{T} M \mathcal{M})$ in female adolescents $(n=410)$ in the permanent dentition. The registration included morphologic occlusion and TMMD clinical

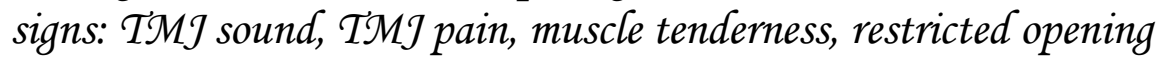
and opening deviation.

The results showed that one or more clinical signs were recorded in $25.6 \%$ of the subjects.

TMMD was associated significantly with posterior crossbite, anterior crossbite, functional shift and midline shift. $\mathcal{N} o$ association was found between $\mathcal{T M} \mathscr{D}$ and molar relationship, overjet, overbite and crowding.

\section{INTRODUCTION}

Specific etiologic factors for Temporomandibular disorders (TMD) have not been found, and today it is still believed that the etiology is multifactorial. ${ }^{(1)}$ Malocclusion has been considered one of the etiologic factors of temporomandibualr dysfunction. $^{(2,3)}$ Different studies investigating the association of occlusal problems and TMD have been published; some were cross sectional others longitudinal. While most of these studies reported association of certain morphologic malocclusions with TMD. ${ }^{(4-12)}$ Other studies showed no significant correlation between TMD and malocclusion. ${ }^{(13-17)}$ In the Western region of Saudi

\footnotetext{
* Associate Professor Department of Preventive Dental Sciences Orthodontic Division, Faculty of Dentistry King Abdul Aziz University Jeddah, Saudi Arabia
} 
Arabia the correlation between occlusal characteristics and TMD was only reported in children in the primary dentition. ${ }^{(18)}$

The aim of the present study is to investigate the potential association between morphologic malocclusion and signs of TMD in a group of adolescent females in the western region of Saudi Arabia.

\section{Materials and Methods}

The sample consisted of female school children attending the seventh, eighth and ninth grade; their age range was $12-16$ years. Private and public schools were selected using a stratified selection technique from different locations in the city of Jeddah in the western region of Saudi Arabia. A total of 520 students were examined but only 410 fit the inclusion criteria. The participants were considered to constitute a reasonably cross-section of healthy Saudi school children in the respective age group.

All students attending on the day of examination were included. Inclusion criteria were: all in permanent dentition stage, no present or previous orthodontic treatment, the absence of any clefts or craniofacial anomalies.

\section{Clinical Examination}

The examination was carried out by two examiners from the department of Preventive Oral Sciences, an Orthodontist and a Pediatric Dentist. Inter and intra examiners calibration and standardization was done prior to the commencement of the study. The examinations on the students were carried out in the schools under proper lighting. The students were seated upright during the intra and extra oral examination of occlusion and signs of Temporomandibular Joint Disorders (TMD). For each student a four-page registration chart was designed to include all TMD and occlusion criteria. A consent form was also obtained from students and their parents for participating in the study.

\section{Examination of Occlusion}

With the teeth in centric occlusion, the anterior-posterior, transverse and vertical relationships were examined and recorded as follows:

\section{Sagittal relationship:}

1. Molar relationship was recorded as Angle Class I (neutrocclusion) Class II (distocclusion) and Class III (mesiocclusion).

2. Overjet was recorded as the horizontal distance between the facial surface of the mesial corner of the most protruded upper central incisor and the facial 
surface of the corresponding lower incisor recorded in millimeters using a periodontal probe. It was recorded as: $0-2 \mathrm{~mm}, 3-6 \mathrm{~mm}$, more than $6 \mathrm{~mm}$ or negative overjet.

3. Anterior crossbite (one or more maxillary incisors occluded lingual to the mandibular incisor.

\section{Vertical relationships:}

1.Overbite was recorded as the vertical distance between the incisal edge of the most protruded upper central incisor and the incisal edge of the corresponding lower incisor using a periodontal probe. Overbite measured as: $0 \mathrm{~mm}$ (edge-edge); $\leq 50 \%, \geq 50 \%$.

2. Anterior openbite: $>0 \mathrm{~mm}$

3.Lateral openbite (lack of contact between at least two pairs of antagonists).

\section{Transversal relationships:}

1.Posterior crossbite was recorded as unilateral or bilateral when one or more of the maxillary molars occluded lingual to the buccal cusps of the opposing mandibular teeth.

2. Scissor bite (unilateral or bilateral) was recorded when one or more maxillary molars occluded buccal to the surfaces of the corresponding mandibular teeth.

3. Midline displacement (shift) of $>2 \mathrm{~mm}$ was assessed by: examining visually the midline of the dentitions, while in centric occlusion. This was further confirmed by using a dental floss from the forehead of the child along the midline of the nose down to the chin, while the child parts the lips and the dentition were still in centric occlusion.

IV. Crowding, maxillary and mandibular, was recorded only in the anterior region when the incisors showed signs of overlapping or rotation or when there was lack of space of $>3 \mathrm{~mm}$.

\section{Examination of TMD}

1. TMJ sound: Digital palpation ${ }^{(19)}$ of the TMJ was done using the middle and index fingers during opening and closure of the mouth. ${ }^{(20)}$

2. Muscular disorder: Digital palpation of the TMJ and associated muscles was performed to detect tenderness using the index, middle and third finger. The masseter, temporalis and the sternoclavicular muscles were palpated bilaterally for tenderness according to the method of Vanderas. ${ }^{(5)}$ The TMJ 
was also assessed for tenderness during mandibular movement according to the method of Dworkin. ${ }^{(21)}$

3. Range of the mandibular motion: The amplitude of maximum vertical opening (MVO) was recorded using a Boley gauge. The gauge was placed on the mandibular incisor edge adjacent to the midline. The child was asked to open as wide as possible and the inter-incisal distance measurement was recorded. This process was repeated twice, and the average was obtained. The overbite value was added to the measurement to obtain the MVO. In cases of openbite the inter-incisal distance was subtracted to obtain the exact MVO. ${ }^{(22)}$ The opening deviation was defined as the displacement of the mandible at least $2 \mathrm{~mm}$ to the right or left of an imaginary vertical line when the mandible had reached half of its vertical opening. The child was asked to open the mouth slowly and this was repeated several times for confirmation. ${ }^{(20)}$

A child was diagnosed as having TMD, if there is any single positive finding in the TMJ, the muscles or the opening criteria presented above.

\section{Statistical Analysis}

Statistical analysis was done using SPSS package. The chi-square method was used to determine the association between the different TMD signs and morphological malocclusion. The level of significance was set at $\mathrm{P}<0.05$.

Inter- and intra- observer reliability between the two examiners were 0.93 , 0.94 , respectively.

\section{RESULTS}

The prevalence of the different morphological occlusal characteristics for the 410 subjects is presented in Table 1. Angle's molar classification class I was the most common, $76.3 \%$, followed by Class II $17 \%$ and Class III was $5.1 \%$. Posterior crossbite was $15.9 \%$, excessive overjet was $5.4 \%$, open bite was $7.1 \%$ and excessive overbite was $18.1 \%$. The maxillary crowding $20.2 \%$ and the mandibular crowding was $23 \%$.

Table 2 presents prevalence of TMD signs, $25.6 \%$ of the subjects had at least one sign. TMJ sound was the most common (15\%) followed by restricted jaw opening $(6 \%)$, and opening deviation $(5.1 \%)$. TMJ pain $(2 \%)$ and muscle tenderness were rare $(0.3 \%)$ 
The association between the occlusal characteristics and different TMD variables are shown in Tables 3 - 6. There was no association between TMD signs and molar relation (table 3), overbite (table 5) or overjet (table 6). Table 3 shows that significant association was found between TMJ sounds and posterior crossbite $(p<0.001)$, functional shift $(p<0.05)$ and midline shift $(p<0.05)$. Significant association was also found between restricted opening and midline shift $(\mathrm{p}<0.001)$, posterior crossbite $(\mathrm{p}<0.01)$ and anterior crossbite $(\mathrm{p}<0.05)$.TMJ pain was significantly associated with posterior crossbite only $(p<0.001)$. Opening deviation was found to associate highly with anterior crossbite $(p<0.001)$.

Table 1: Distribution and prevalence of occlusal characteristics in female adolescents $(n=410)$

\begin{tabular}{|c|c|c|c|c|c|}
\hline Occlusal Variable & $\mathbf{n}$ & $\%$ & Occlusal Variable & $\mathbf{n}$ & $\%$ \\
\hline Molar Classification & & & Overjet & & \\
\hline Class I & 313 & 76.3 & $-\mathrm{ve}$ & 15 & 3.7 \\
\hline Class II & 70 & 17 & $0-2$ & 235 & 57.3 \\
\hline \multirow[t]{2}{*}{ Class III } & 21 & 5.1 & $3-6$ & 138 & 33.7 \\
\hline & & & $>6$ & 22 & 5.4 \\
\hline Canine Classification & & & Overbite & & \\
\hline Class I & 283 & 69 & $\geq 50 \%$ & 74 & 18.1 \\
\hline Class II & 108 & 26.3 & $\leq 50 \%$ & 2.76 & 67.3 \\
\hline \multirow[t]{2}{*}{ Class III } & 14 & 3.4 & Edge/edge & 30 & 7.3 \\
\hline & & & Open bite & 29 & 7.1 \\
\hline Posterior open bite & 6 & 1.5 & Anterior cross bite & 41 & 10.0 \\
\hline Posterior cross bite & 65 & 15.9 & Midline shift & 160 & 39 \\
\hline Unilateral & 45 & 10.7 & & & \\
\hline Bilateral & 22 & 5.2 & Maxillary crowding & 83 & 20.2 \\
\hline Functional shift & 7 & 1.7 & Mandibular crowding & 94 & 23 \\
\hline Scissor bite & 3 & 0. & Attrition & 10 & 2.4 \\
\hline
\end{tabular}


Egyptian

Orthodontic Journal

Table 2: Prevalence of TMD sign among female adolescents (410)

\begin{tabular}{|l|c|c|}
\multicolumn{1}{c|}{$\begin{array}{c}\text { Signs } \\
\mathbf{n = 4 1 0}\end{array}$} & $\mathbf{n}$ & \% \\
\hline TMJ sounds & 65 & 15.8 \\
\hline TMJ pain & 12 & 2.9 \\
\hline Muscle tenderness & 1 & 0.2 \\
\hline Restricted opening & 24 & 6.0 \\
\hline Opening deviation & 21 & 5.1 \\
\hline At least one sign & 105 & 25.6 \\
\hline
\end{tabular}

Table 3: Percentage Distribution of TMD disorders according to molar classification $(n=410)$

\begin{tabular}{|c|c|c|c|c|}
\hline \multirow[b]{2}{*}{ TMD signs } & \multicolumn{3}{|c|}{ Molar Classification } & \multirow[b]{2}{*}{ P value* } \\
\hline & $\begin{array}{l}\text { Class I } \\
76.5 \%\end{array}$ & $\begin{array}{c}\text { Class II } \\
17.4 \%\end{array}$ & $\begin{array}{c}\text { Class III } \\
5.1 \%\end{array}$ & \\
\hline TMJ sounds & 15.7 & 17.1 & 4.8 & ns \\
\hline TMJ pain & 2.6 & 4.3 & 0 & $\mathrm{~ns}$ \\
\hline Muscle Tenderness & 0 & 1.4 & 0 & ns \\
\hline Restricted Opening & 6.1 & 2.9 & 4.8 & $\mathrm{~ns}$ \\
\hline Opening Deviation & 5.1 & 5.7 & 4.8 & ns \\
\hline At least one sign & 25.9 & 24.3 & 9.5 & $\mathrm{~ns}$ \\
\hline
\end{tabular}

* Pearson's chi-square

ns: non significant

Volume 30 - December 2006 
Egyptian

Orthodontic Journal

Table 4: Percentage distribution of malocclusion with TMD signs $(n=410)$

\begin{tabular}{|l|c|c|c|c|c|c|}
\hline \multicolumn{1}{|c|}{ TMD Signs } & $\begin{array}{c}\text { Posterior } \\
\text { Crossbite } \\
\mathbf{1 5 . 9 \%}\end{array}$ & $\begin{array}{c}\text { Functional } \\
\text { Shift } \\
\mathbf{1 . 7 \%}\end{array}$ & $\begin{array}{c}\text { Anterior } \\
\text { Crossbite } \\
\mathbf{1 0 . 0 \%}\end{array}$ & $\begin{array}{c}\text { Midline } \\
\text { Shift } \\
\mathbf{3 9 . 0 \%}\end{array}$ & $\mathbf{3 0 . 0 \%}$ & $\mathbf{2 . 4 \%}$ \\
\hline TMJ sound & $30.8^{* *}$ & $42.9^{*}$ & 22.0 & $19.4^{*}$ & 19.5 & 0 \\
\hline TMJ pain & $9.2^{* *}$ & 14.3 & 7.3 & 3.1 & 3.3 & 0 \\
\hline Muscle tenderness & 1.5 & 0.0 & 0.0 & 0.6 & 0 & - \\
\hline Restricted opening & $7.7 *$ & 0.0 & $14.6^{*}$ & $10.0 * *$ & 5.7 & 0 \\
\hline Opening deviation & 6.3 & 14.3 & $14.6^{* *}$ & 5.6 & 4.1 & - \\
\hline At least one sign & $47.7 * *$ & $57.1 *$ & $48.8^{* *}$ & $33.1 * *$ & 29.3 & 0 \\
\hline
\end{tabular}

ns: non significant

$* \mathrm{p}<0.05$

$* * \mathrm{p}<0.00$

Table 5: Percentage distribution of overjet with TMD $(n=410)$

\begin{tabular}{|l|c|c|c|c|c|}
\hline \multirow{2}{*}{ TMD signs } & -ve & $\mathbf{0 - 2}$ & $\mathbf{3 - 6}$ & $\mathbf{> 6}$ & \multirow{2}{*}{ P value } \\
\cline { 2 - 5 } & $\mathbf{3 . 6 \%}$ & $\mathbf{5 6 \%}$ & $\mathbf{3 3 \%}$ & $\mathbf{5 . 3 \%}$ & \\
\hline TMJ sound & 13.3 & 12.8 & 18.1 & 18.2 & $\mathrm{~ns}$ \\
\hline Associated TMJ pain & 6.7 & 2.1 & 3.6 & 4.5 & $\mathrm{~ns}$ \\
\hline Muscle tenderness & - & 0.4 & - & - & $\mathrm{ns}$ \\
\hline Restricted opening & 13.3 & 6.4 & 4.3 & 4.5 & $\mathrm{~ns}$ \\
\hline Deviation & 13.3 & 4.7 & 3.6 & 9.1 & $\mathrm{~ns}$ \\
\hline At least one sign & 46.7 & 21.7 & 26.1 & 27.3 & $\mathrm{~ns}$ \\
\hline
\end{tabular}

ns: non significant

Volume 30 - December 2006 
Egyptian

Orthodontic Journal

Table 6: Percentage distribution of overbite with TMD $(n=410)$

\begin{tabular}{|l|c|c|c|c|c|}
\hline \multirow{2}{*}{\multicolumn{1}{|c|}{ TMD signs }} & $\mathbf{2 5 0}$ & $\mathbf{5 0}$ & Edge-edge & Openbite & \multirow{2}{*}{ P value } \\
\cline { 2 - 6 } & $\mathbf{1 8 \%}$ & $\mathbf{6 7 . 5 \%}$ & $\mathbf{7 . 3 \%}$ & $\mathbf{7 . 1 \%}$ & \\
\hline TMJ sound & 12.2 & 15.2 & 16.7 & 17.2 & $\mathrm{~ns}$ \\
\hline Associated TMJ pain & 1.4 & 2.5 & 3.3 & 6.9 & $\mathrm{~ns}$ \\
\hline Muscle tenderness & - & 0.4 & - & - & $\mathrm{ns}$ \\
\hline Restricted opening & 5.4 & 5.1 & 6.7 & 13.8 & $\mathrm{~ns}$ \\
\hline Deviation & 6.8 & 4.0 & 6.7 & 6.9 & $\mathrm{~ns}$ \\
\hline At least one sign & 21.6 & 23.2 & 33.3 & 31.0 & $\mathrm{~ns}$ \\
\hline
\end{tabular}

ns: non significant

\section{DISCUSSION}

Considerable controversy exists in the literature as to whether or not craniomandibular disorders are produced in association with malocclusion. ${ }^{(17,23,}$ 24, 25) The present study has shown that some morphological malocclusions are more important than others in relation to TMD.

Posterior crossbite was present in $15.9 \%$ of the sample. It was found to be associated with TMD, specifically TMJ sound, TMJ pain and restricted opening of the jaw. These results are consistent with other reports from the literature. ${ }^{(26,4}$, $6,8.11,18)$

More specifically $30.8 \%$ of subjects with posterior crossbite were found to have TMJ sound, which is in agreement with reports from earlier studies. ${ }^{(4,27,28)}$ More recently reports from longitudinal studies have shown that prolonged presence of crossbite predisposed $\mathrm{TMD}^{(29,12,16)}$ indicating that this type of malocclusion deserves further considerations. ${ }^{(25)}$

Anterior crossbite or negative overjet has been reported to associate with TMD. ${ }^{(3,4,27)}$ This is consistent with the present study where anterior crossbite was found to be significantly associated with opening deviation and restricted jaw opening. 
Furthermore, some longitudinal studies reported that 15 -years-old who originally had anterior crossbite or edge-to-edge incisor relationship at age ten were more likely to have limited jaw movements in adolescence. ${ }^{(30)}$

Midline shift was found to significantly correlate with TMJ sound and restricted jaw opening. It is interesting to find that other related occlusal characteristics such as functional shift, midline shift and crossbite were also significantly associated with TMJ sounds.

Distal and mesial molar occlusion as such or associated with occlusal interferences have been suggested to pre-dispose an individual to TMD. ${ }^{(3,27,31,32)}$ Mesial molar relation or class III has been reported to relate to muscle tenderness ${ }^{(30)}$ moderate and severe dysfunction ${ }^{(11)}$ and clinical TMD signs in general. ${ }^{(33)}$ However, contradictory results have also been reported. ${ }^{(5,34,35)}$ As in the present study, no correlation was found between TMD signs and molar classification.

Anterior open bite has been reported to be associated with TMD signs and symptoms in different studies. ${ }^{(33,4,11)}$ However this has not been found in some studies ${ }^{(10,6,17)}$ nor has it been found in the present study. The reason may be due to the low prevalence of open bite in the present sample.

Contradictory reports have been published regarding the presence of deep overbite and TMD. .Although deep bite has been found to positively correlate to TMD in children and adolescents ${ }^{(36,5,4)}$, however no such correlation has been found among adolescents in the present sample nor has it been found in reports from longitudinal studies in adults ${ }^{(37)}$ nor in adolescents. ${ }^{(7,38)}$ Furthermore, Magnusson et al reported recently that individuals who had deep bite at baseline did not turn out to have any increased risk of developing subjective symptoms of TMD. ${ }^{(25)}$

Excessive overjet has not been found in the present study to correlate with TMD, corroborating results in other studies. ${ }^{(4,6,13,14)}$ However, excessive overjet has been shown to correlate with dysfunction of the masticatory system. ${ }^{(27,7,32,11)}$ On the other hand excessive overjet when associated with distal molar occlusions, were found to correlate or predispose TMD. ${ }^{(30,7,39)}$ Although, some studies found significant relationships between occlusal factors and clinical signs of TMJ dysfunction, many studies showed lack of significance between the type of occlusal variables and the sign and symptom of TMJ dysfunction. ${ }^{(8)}$

In an extensive review of the literature, Seligman and Pullinger ${ }^{(23)}$ concluded that published research suggests a limited role for intercuspal occlusal 
factors in the cause of TMD. Similarly, Tallents et $\mathrm{al}^{(40)}$ in a literature review determined that there may not be a strong association between incisal relationship, condylar position and TMD.

There seems, however to be a great variation in susceptibility of the stomatognathic system from subject to subject and therefore, the same etiological factor in different individuals might cause different symptoms.

In conclusion, the present investigation on adolescent females has revealed that TMD was significantly correlated with posterior cross-bite, midline shift, anterior cross bite, and functional shift. The question of whether or not early treatment of such occlusal problems will prevent development of TMD or decrease TMD signs in the future is still an open area for research and more longitudinal studies.

\section{REFERENCES}

1. American Academy of Orofacial Pain: In: McNeil C, Ed. Temporomandibular disorders: guidelines for classification, assessment, and management, Chicago. Quintessence; 1993, p:27-38.

2. Ingervall B, Hedegard B: Subjective evaluation of functional disturbances of the masticatory system in young Swedish men. Community Dent Oral Epidemiol 1974;2:149-52.

3. Mohlin B, Ingervall B, Thilander B: Relation between malocclusion and mandibular dysfunction in Swedish men. Eur J Orthod 1980; 2:229-38.

4. Brandt D: Temporomandibular disorders and their association with morphologic malocclusion in children. In: Developmental Aspects of temporomandibular joint disorders, Carlson DS, McNamara JA Jr, Ribbens KA EDS. Ann Arbor, MI: Center for Growth and Development, 1985, pp 279-98.

5. Lieberman MA, Gazit E, Fuchs C, Lilos P: Mandibular dysfunction in 10-18-year-old school children as related to morphological malocclusion. $1985 ; 12: 209-14$.

6. Vanderas AP: The relationship between craniomandibular dysfunction and malocclusion in white children with unilateral cleft lip and cleft palate. Cranio, 1989;7:200-204.

7. Egermark-Eriksson I, Carlsson GE, Magnusson T, Thilander B: A longitudinal study on malocclusion in relation to signs and symptoms of cranio-mandibular disorders in children and adolescents. Eur J Orthod 1990;12:399-407. 
8. Kritsineli M, Shim YS: Malocclusion, body posture, and temporomandibular disorder in children with primary and mixed dentition. J Clin Pediatr Dent 1992;16:86-93.

9. Venderas AP: Relationship between craniomandibular dysfunction and malocclusion in white children with and without unpleasant life events. $\mathbf{J}$ Oral Rehab 1994;21:177-83.

10. Sari S, Sonmez H, Oray GO, Camdeviren H: Temporomandibular dysfunction and occlusion in the mixed and permanent dentition. J Clin Pediatr Dent 1999;24:59-62.

11. Thilander B, Rubio G, Pena L, de Mayorga C: Prevalence of temporomandibular dysfunction and its association with malocclusion in children and adolescents: an epidemiologic study related to specified stages of dental development. Angle Orthod 2002;72:146-154.

12. Mohlin BO, Derweduwen K, Pilley R, Kingdon A, Shaw WC, Kenealy P: Malocclusion and temporomandibular disorders: a comparison of adolescents with moderate to severe function with those without signs and symptoms of temporomandibular disorders and their further development to 30 years of age. Angle Orthod 2004;74:319-327.

13. Nilner M: Relationships between oral parafunctions and functional disturbances and diseases of the stomatognathic system among children aged 7-14 years. Acta Odontol Scand 1983;41:167-72.

14. Nilner M: Relationship between oral parafunctions and functional disturbances in the stomagnathic system among children 15-18 years old. Acta Odontol Scand 1983;41:197-201.

15. Nesbit BA, Moyers RE, TenHave TR: Adult temporomandibular joint disorder symptomatology and its association with childhood occlusal relations: a preliminary report. In Developmental aspects of temporomandibular joint disorders, Carlson DS, McNamara JA Jr, Ribbens KA, EDS, Ann Arbor, MI: center for Human growth and development. 1985; pp 183-89.

16. De Boeven JA, van den Berghe: Longitudinal study of functional conditions in the masticatory system in Flemish children. Community Dent Oral Epidemiol 1987;15:100-103.

17. Gunn SM, Woolfolk MW, Faja BW: Malocclusion and TMJ symptoms in migrant children. J Craniomandib Disord 1988;2:196-200. 
18. Alamoudi N: The correlation between occlusal characteristics and temporomandibular dysfunction in Saudi Arabian children. J Clin Pediatr Dent 2000; 24:229-236.

19. Goho $\mathbf{C}$ and Jones HL: Association between primary dentition wear and clinical temporomandibular dysfunction signs. Pediatric dentistry 1991; 13:263.

20. Gross A and Gale EN: Prevalence study of the clinical signs associated with mandibular dysfunction. J Am Dent Ass 1983. 107:932.

21. Dworkin S, Huggins KH, LeReche I, Von Korff M, et al: Epidemiology of signs and symptoms in temporomandibular disorders. Clinical signs in cases and control. JADA 1990;120:273-81.

22. Okeson JP: Assessment of orofacial pain disorders, In: Okeson JP orofacial pain: guidelines for assessment, diagnosis and management. $3^{\text {rd }}$ ed. American Academy of Orofacial pain. Chicago: Quintessence;1996: 19-44.

23. Seligman D, Pullinger A: The role of intercuspal occlusal relationship in temporomandibular disorders: a review. J Craniomandib Disord Facial Oral Pain 1991; 5:96-106.

24. Kirveskari P, Alanen P, Jamsa T: Association between craniomandibular disorders and occlusal interferences in children. J Prosthet Dent 1992 May; 67:692-696.

25. Magnusson T, Egermarki I, Carlsson GE: A prospective investigation over two decades on signs and symptoms of temporomandibular disorders and associated variables. A final summary. Acta Odontol Scand 2005 ;63:99-109.

26. Egermark-Eriksson I: Mandibular dysfunction in children and in individuals with dual bite (thesis). Swed Dent J 1982;supp.10: 1-45

27. Riolo M L, Brandt D, TenHave T R: Association between occlusal characteristics and signs and symptoms of TMJ dysfunction in children and young adults. Am J Orthod Dentofacial Orthop 1987; 92: 467-477.

28. Moyers RE: The development of occlusion and temporomandibular joint disorders. In: Carlsson DS, McNamara JA Jr, Ribbens KA, eds, Developmental aspects of temporomandibular joint disorders. Monograph16. Craniofacial Growth Series Ann Arbor: Center for Human Growth and Development. 1985: 49-70.

29. Egermark I, Magnusson T, Carlsson GE: A 20-year follow-up of signs and symptoms of temporomandibular disorders and malocclusions in subjects with and without orthodontic treatment in childhood. Angle Orthod 2003;73:109-115. 
30. Pahkala RH, Laine-Alava MT: Do early signs of orofacial dysfunctions and occlusal variables predict development of TMD in adolescence? J Oral Rehabil 2002;29:737-743.

31. Egermark-Eriksson, I, Carlsson, G.E., Magnusson, T. and Thilander, B: The dependence of mandibular dysfunction in children on functional and morphologic malocclusion. Am J Orthod. 1983;187.

32. Henrikson T, Ekberg EC, Nilner M: Symptoms and signs of temporomandibular disorders in girls with normal occlusion and Class II malocclusion. Acta Odontol Scand 1997;55:229-35.

33. Mohlin B, Thilander B: The importance of the relationship between malocclusion and mandibular dysfunction and some clinical applications in adults. Eur J Orthod 1984;6:192-204.

34. Pullinger AG, Seligman DA, Gornbein JA: A multiple logistic regression analysis of the risk and relative odds of temporomandibular disorders as a function of common occlusal features. J Dent Res 1993; 72:968-979.

35. Keeling S, McGorray S, Wheeler $\mathbf{T}$ and King G: Risk factor associated with temporomandibular joint sounds in children 6 to 12 years of age. Am J Orthod Dentofac Orthop 1994;105:279-287.

36. Williamson EH: Temporomandibular dysfunction in pretreatment adolescent patients. Am J Orthod. 1977;72:429-433.

37. Mohlin, B: Need for orthodontic treatment with special reference to mandibular dysfunction. A study in men and women. Thesis, University of Gotherenburg, 1982

38. Wanman A: Craniomandibular disorders in adolescents. A longitudinal study in an urban Swedish population. Swed Dent J Suppl. 1987; 44:1-61.

39. Zimmer B, Jager A, Kubein-Meesenburg D: Comparison of 'normal' TMJ-function in Class I, II, and III individuals. Eur J Orthod 1991; 13:27-34.

40. Tallents RH, Catania J, Sommers E: Temporomandibular joint findings in pediatric populations and young adults: a critical review. Angle Orthod 1991; 61:7-16. 